\title{
Attitudes towards the risk of HIV transmission in sport
}

\author{
S Reddy (M Sport Science) \\ Y Coopoo (D Phil, FACSM)
}

Department of Sport Science, University of KwaZulu-Natal, Durban

\begin{abstract}
Objective. There is a real risk of transmitting HIV through open wounds during participation in sport. The aim of this study was to investigate athlete s knowledge and attitudes towards HIV transmission in a competitive sport environment how their sporting codes, demographics, knowledge and interaction with colleagues influenced their attitudes.

Design. A questionnaire was administered to elite athletes $(N=575)$ competing in 11 sport codes including high, medium and low-risk sports, and undergraduate students $(N=46)$ from a Sport Science Department. Athletes from all economic backgrounds, who competed at national, provincial or at first-division level, were included in this study. The questionnaire was distributed during national tournaments and training sessions.
\end{abstract}

Results. Sixty-three per cent of athletes believed that a risk of HIV transmission exists in sport participation. Fiftyeight per cent believed that they had a right to know if a teammate/opponent was HIV-positive, and $62 \%$ believed that all athletes should be tested for HIV. Fifty per cent of the respondents indicated that they would participate against individuals who were HIV-positive. Most athletes (88\%) believed that more education on HIV transmission in sport was needed and $58 \%$ felt that HIV should be a notifiable disease in sport. Forty-six per cent of the athletes indicated that they would participate in competition even though they were HIV-positive.

Conclusion. The threat of infection or transmission did not deter athletes who were afflicted or unafflicted with HIV from participating in competitive sports.

\section{CORRESPONDENCE:}

\author{
Y Coopoo \\ University of KwaZulu-Natal \\ Private Bag X54001 \\ Durban \\ 4000 \\ Tel: 031 - 2607394 \\ Fax: 031 - 2607903 \\ E-mail: coopooy@ukzn.ac.za
}

\section{Introduction}

A survey conducted by the South African Sports Commission in $2002^{41}$ showed the number of participants in all sports to be 14.7 million. This translates to approximately 10 million adults participating in sport. Many adults participate in more than 1 sport. The average estimate is 1.5 sports per person. The sporting fraternity has to take cognizance of AIDS and its transmission and impact on sport because the probability of encountering an AIDS-infected person during sport is high. About 375670 South Africans were expected to die from HIVIAIDS in 2003, an increase of more than $30 \%$ of the estimated 219660 AIDS-related deaths in 2000, according to projections by the Human Sciences Research Council. ${ }^{31}$

The attitude of health care professionals has added to the confusion regarding the spread of the HIV virus. These professionals wear gloves while treating patients, yet maintain at the same time that the risk of transmission is very low. ${ }^{10}$

In America a large number of leading sports personalities have made their HIV status public. These popular sports heroes have contributed towards demystifying the disease and have created greater public awareness by educating the public on the disease. This has not occurred in South Africa. Those most affected by HIV transmission are $18-25$ year old. This age group has the highest number of individuals participating in sports..$^{11,22,29}$ These young adults play a central role in social, economic and political activities. Any epidemic that threatens to deplete this cohort, undermines the social, economic and demographic stability of society. ${ }^{19}$

The HIVIAIDS barometer on estimated HIV infections worldwide stood at 58580614 at $05 \mathrm{~h} 00$ on Wednesday 11 August 2004 . $^{32}$ The sports environment is a social, recreational, economic and competitive arena providing opportunities for interaction and a venue for transmission. Competitive athletes are usually drawn from an economically active sector of the population. ${ }^{5}$ These athletes form part of an elite group which one would presume to be knowledgeable about HIVIAIDS. Therefore the focus of this study was to ascertain the attitudes of sportspersons involved in contact and non-contact sports, towards HIV-positive individuals in a competitive sport environment and the risk of HIV transmission through sport.

Calabrese ${ }^{10}$ concluded that the HIV transmission risk in a sporting environment is very low. Brown et al. ${ }^{8}$ calculated the risk of HIV transmission through sport to be less than 1 infection per 85647821 game contacts. The Centers for Disease Control and Prevention ${ }^{13}$ placed the odds of contracting HIV during a sporting event to be greater than a million to 1 . 
No studies have documented athlete-to-athlete transmission from blood exposure on the playing field, except for 1 anecdotal report of an Italian soccer player. ${ }^{16,48}$ In this incident both players clashed, sustaining open, bleeding wounds resulting in possible mixing of blood. This was the first documented case, published in 1990, of HIV transmission that occurred directly as a result of sports participation. At present, accurate data on HIV transmission during sports participation is only available for American football players and professional boxers in South Africa. In American football the risk of HIV transmission has been calculated to occur at a rate of approximately 1 player per 100000000 games. In a boxing match of 12 rounds, the risk of an open bleeding wound has recently been calculated at $47 \%$. In a study ${ }^{42}$ of 952 boxers in South Africa HIV disease was determined at $9 \%$ and the risk of contact between boxers during a fight at $100 \%$. The risk of infection among professional South African boxers has been calculated at 1 infection in 4760 fights. $^{42}$

According to Gatheram ${ }^{19}$ there is a need for an inter-sectoral response to HIVIAIDS. It is fundamental that HIV is not seen as merely a health issue, for it is indeed much more than that. It is a welfare issue, a legal issue, an educational issue, a human rights issue, and a sports issue. For these reasons alone it is of paramount importance that the role of sport and HIVIAIDS be utilised to unite our diverse country around this human issue..$^{19}$

\section{Methods}

The study design was that of a questionnaire survey consisting of 22 questions. The questionnaire was designed to assess variables that influence athletes attitudes towards the risk of HIV transmission of through sport. The research questionnaire was influenced by a similar study conducted by Calabrese ${ }^{10}$ in 1993, which was confined only to college students and did not differentiate between risk categories. In the present study the questionnaire was amended to include variables that might have an influence on the formation of attitude to HIV. These variables included demographics, knowledge and fear of transmission, knowledge or lack of knowledge on the benefits of exercise in HIV-infected individuals, and the influence of health care workers, sports personnel and the media in HIVIAIDS education. Questions were divided into 4 major categories namely: (i) demographic data that could influence attitude formation; (ii) analysing responses to gauge attitude, knowledge and fears about HIV transmission in sport; (iii) assessing athletes knowledge of the benefits of exercise in HIV-infected individuals; and (iv) the influence of health care workers, sports personnel and the media in promoting education and awareness of HIVIAIDS in sport

Questionnaires were administered to 22 sports clubs, comprising 11 sport codes. Participants were categorised into the following risk categories: (i) high-risk (173 respondents) comprising boxing $(N=14)$, karate $(N=44)$, wrestling $(N=52)$, and rugby $(N=63)$; (ii) medium-risk (201 respondents) comprising field hockey $(N=45)$, basketball $(N=46)$, volleyball $(N=50)$, and soccer $(N=60)$; and (iii) low-risk (201 respondents) comprising tennis $(N=34)$, athletics $(N=60)$, and swimming $(N=$ 61). Sport science students $(N=46)$ were included in the lowrisk category as this was a mixed group of athletes participating at a high level of sport.

During the period between January 2001 and August 2001, 900 questionnaires were handed out to athletes competing at provincial or national level, or in a first-division club. These athletes were selected randomly. Five hundred and seventy-five questionnaires were completed. This resulted in a response rate of $64 \%$. The gender balance for returned questionnaires was 378 males to 193 females, with 4 respondents not disclosing their gender.

The researchers administered most of the questionnaires. The balance were administered by colleagues from the Sport Science Department, and administrators of various sports institutions and clubs.

The majority of the questions required that the athletes place a tick in the relevant block. There were 11 yes or no questions. Open-ended questions formed part of the questionnaire, countering the restrictive nature of responses confined only to the alternatives provided.

The researchers and a team of colleagues visited approximately 22 clubs during administration of the questionnaires.

Further data were collected at tertiary institutions and selected competitive tournaments and matches.

The instructions for answering the questionnaire were clear. The athletes co-operation was sought in this study; it was explained that participation was completely voluntary and that all responses would be kept strictly confidential. Athletes signed informed consent to participate in the study. Ethical clearance was obtained from the University of KwaZulu-Natal (Westville campus). No names were written on the questionnaires, thus maintaining the anonymity of the responses.

\section{Analysis}

The completed questionnaires were entered into a database, checked for inconsistencies, and spoilt forms were removed from the analysis. Statistics were compiled by the Department of Statistics at the University of Kwa-Zulu-Natal. The SPSS version 9, library of statistical packages was used to compute the descriptive statistics reported in this study (Microsoft SPSS (version 9) standard version, Windows 2001). Since there is no comparative study of this nature in South Africa, no inferential statistics comparing results with different provinces could be analysed.

\section{Results}

The results reported refer to the attitudes of athletes towards the risk of HIV transmission in a sporting environment. The study assumed that the athletes answered the questions truthfully and sincerely. However this is an inherent limitation of questionnaire studies. Table I shows the demographic data of the sample.

Sixty-six per cent of athletes in the study were male, and 
33\% female respectively (Table I). A study by the South African Sports Commission ${ }^{41}$ concluded that more males participated in sport than females, at $46 \%$ versus $27 \%$. The majority of athletes (46\%) surveyed in this sample fell into the 19 25 -year age group. This is also the most sexually active group, therefore most at risk of HIV infection. ${ }^{1,42}$ Research in the USA has repeatedly found that approximately $21 \%$ of AIDS cases involve people aged $20-29$ years. ${ }^{24}$

\begin{tabular}{|lll|}
\hline \multicolumn{2}{l}{$\begin{array}{l}\text { TABLE I. Demographic information on respondents } \\
(\boldsymbol{N}=\mathbf{5 7 5 )}\end{array}$} & Number \\
\hline Parameter & & $\%$ \\
\hline Gender & 378 & 66 \\
Male & 193 & 33 \\
Female & 4 & 1 \\
No response & & \\
\hline Age (yrs) & 131 & 23 \\
Under 18 & 266 & 46 \\
19 - 25 & 69 & 12 \\
26 - 31 & 102 & 18 \\
Over 31 & 7 & 1 \\
No response & & \\
\hline Education & 20 & 4 \\
None & 13 & 2 \\
Primary & 233 & 40 \\
High & 300 & 52 \\
Tertiary & 9 & 2 \\
No response & & 32 \\
\hline Income (R/month) & 185 & 9 \\
Below R1 200 & 51 & 41 \\
R1 200 - R2 000 & 237 & 18 \\
Above R2 000 & 102 & \\
No response & & \\
\hline
\end{tabular}

A higher percentage of respondents were in the over-31 age group (18\%) than in the $26-31$ age group $(12 \%)$. More than half $(52 \%)$ of the respondents indicated that they had a tertiary level of education. Generally this is the age group (18 - 25 years) from which most elite athletes are drawn, and many of them are students. ${ }^{29}$

Forty-one per cent of respondents were in the high-income group, which correlates with data obtained on educational background.

General knowledge of HIV transmission was assessed in Table II. The majority of the athletes surveyed (64\%) indicated that touching infected blood posed a risk of transmission. A transmission risk exists only if the skin is broken and infected blood enters through this route. ${ }^{17,44}$ Ninety-two per cent of respondents indicated that sharing needles was a means of transmission, especially among wrestlers and bodybuilders, who share needles used to inject steroids. Two cases have been reported among bodybuilders. ${ }^{21,40}$

Table III investigated athletes knowledge of whether HIV could/could not be transmitted through sport participation.

A large number $(N=355,62 \%)$ of the athletes stated that
TABLE II. General knowledge of HIV transmission ( $N=$ 575)

\begin{tabular}{|c|c|c|c|c|}
\hline \multirow[b]{2}{*}{ Methods of transmission } & \multicolumn{2}{|c|}{$\begin{array}{l}\text { Yes } \\
\text { response }\end{array}$} & \multicolumn{2}{|c|}{$\begin{array}{l}\text { No } \\
\text { response }\end{array}$} \\
\hline & $N$ & $\%$ & $N$ & $\%$ \\
\hline Sexual intercourse & 557 & 97 & 18 & 3 \\
\hline Sharing needles & 528 & 92 & 47 & 8 \\
\hline Blood transfusion & 512 & 89 & 63 & 11 \\
\hline Mother to child & 455 & 79 & 120 & 21 \\
\hline Touching infected blood & 365 & 64 & 210 & 37 \\
\hline Sharing eating utensils & 15 & 3 & 560 & 97 \\
\hline Shaking hands & 10 & 2 & 565 & 98 \\
\hline Hugging a person & 6 & 1 & 569 & 99 \\
\hline
\end{tabular}

TABLE III. Knowledge of HIV transmission through sport, compared by risk category

\begin{tabular}{|c|c|c|c|c|c|}
\hline \multirow[b]{2}{*}{ Risk category } & \multicolumn{5}{|c|}{ HIV transmission through sport } \\
\hline & Yes & No & Unsure & No response & Total \\
\hline \multicolumn{6}{|l|}{ High } \\
\hline Number & 142 & 25 & 4 & & 171 \\
\hline Total\% & 25 & 4 & 1 & & 30 \\
\hline \multicolumn{6}{|l|}{ Medium } \\
\hline Number & 105 & 92 & 1 & & 198 \\
\hline Total\% & 18 & 16 & 0 & & 34 \\
\hline \multicolumn{6}{|l|}{ Low } \\
\hline Number & 108 & 91 & & & 199 \\
\hline Total\% & 19 & 16 & & & 35 \\
\hline \multicolumn{6}{|l|}{ Total } \\
\hline Number & 355 & 208 & 5 & 7 & 575 \\
\hline Total\% & 62 & 36 & 1 & 1 & 100 \\
\hline
\end{tabular}

HIV could be transmitted through sport participation. Twentyfive per cent of respondents in the high-risk category, $18 \%$ in the medium and $19 \%$ in the low-risk category believed that sport involves a risk of HIV transmission. There was a significant difference $(p<0.05 \mathrm{l})$ in attitudes among the various sport codes and risk categories with regard to HIV being transmitted through sport participation.

Various questions were posed to athletes to determine their knowledge of HIV transmission through sport (Table IV). In assessing attitudes towards HIV-positive athletes being allowed to participate in sport (question 1, Table IV), the following was established. An equal percentage (14\%) in the highrisk category responded both positively and negatively towards HIV-positive athletes being allowed to participate in sport. A larger proportion (30\%) in the low-risk category and $27 \%$ in the medium-risk category were willing to participate with HIV-positive individuals. A total of $71 \%$ indicated that HIV-positive athletes should be allowed to participate, as opposed to $25 \%$.

Fear of contracting the HIV virus (question 2, Table IV) was indicated by $59 \%$ of the respondents, while $37 \%$ indicated that they were not afraid. The largest percentage of respondents (24\%), who indicated such fear were in the high-risk category, as these sports posed the most risk of infection. ${ }^{18}$ This correlates with a large number of bleeding injuries encountered in high-risk sports. In the low-risk category, $15 \%$ indicated that they were afraid of contracting the HIV virus. 


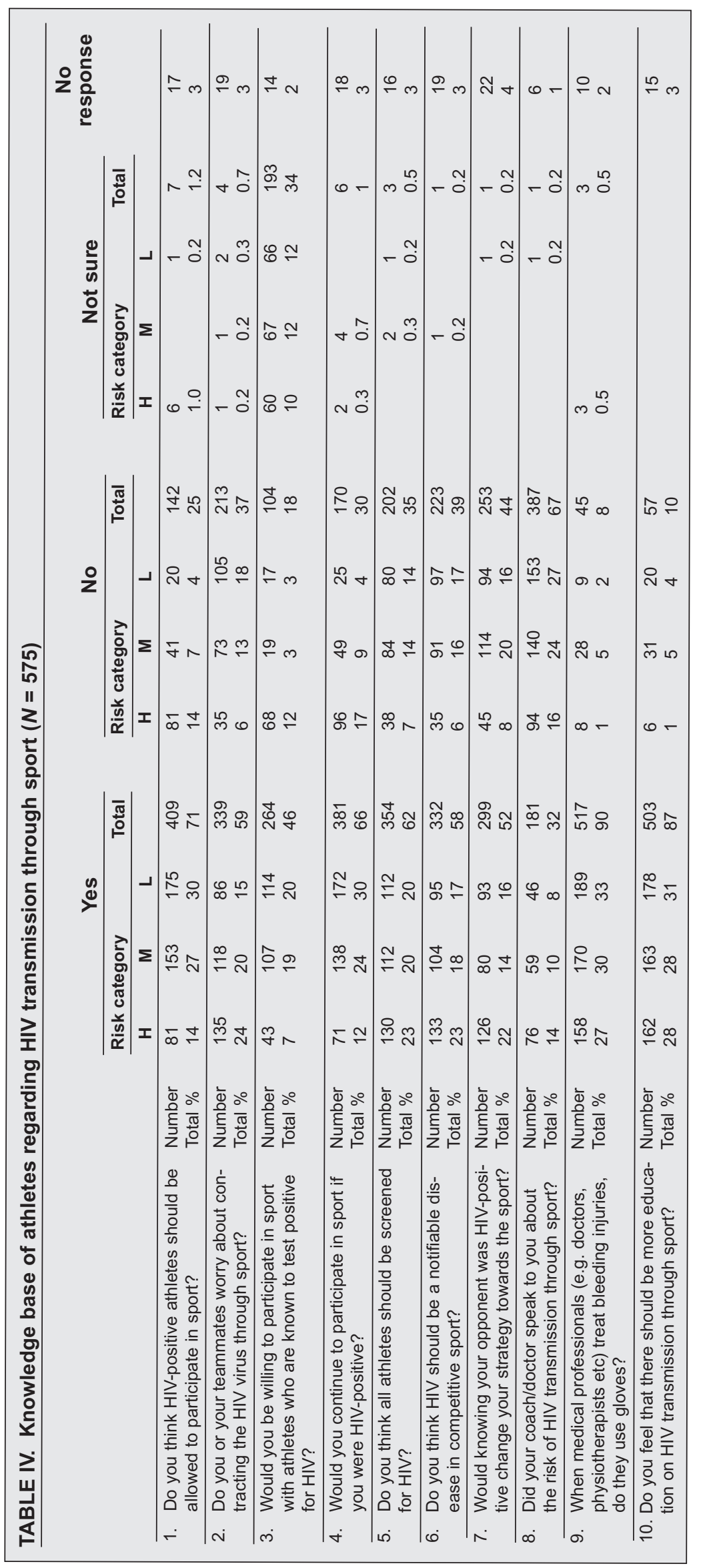


The response to participating with HIV-positive athletes was as follows (question 3, Table IV). In the high-risk category, 12\% of the respondents did not want to participate with athletes known to be HIV-positive, whereas in the low-risk category $20 \%$ and in the medium-risk category $19 \%$ of the respondents agreed to participate against HIV-positive individuals. A majority of the respondents (46\%) were willing to participate with HIV-positive, while $18 \%$ were unwilling, $34 \%$ were not sure how they felt and $2 \%$ did not respond at all.

Most athletes (66\%) indicated that they would continue to participate in sport if diagnosed HIV-positive, against 30\% who indicated that they would not participate (question 4, Table IV). This correlates with a knowledge of the benefits of exercise for HIV-positive individuals. More respondents in the medium (24\%) and low-risk (30\%) categories indicated that they would continue to participate in sport compared with those in the highrisk category (12\%).

Sixty-two per cent of respondents indicated that all athletes should be screened for HIV compared with $35 \%$ who indicated that athletes should not be screened (question 5, Table IV).

Fifty-eight per cent of the sample saw a need for testing in order to make HIV a notifiable disease in sport (question 6 , Table IV). The majority (23\%) of the yes responses came from the high-risk category. This correlates with the high incidence of bleeding injuries in high-risk sport and the greatest fear of contracting the HIV virus. ${ }^{34}$

The majority of respondents (52\%) indicated that knowing their opponent was HIV-positive would influence their game strategy, while $44 \%$ indicated that it would not influence their game strategy (question 7 , Table IV).

Only $32 \%$ of the respondents indicated that they were informed of the risk of HIV transmission through sport by doctors and coaches, while $67 \%$ indicated that they were not (question 8, Table IV).

Respondents were asked whether medical professionals used gloves when treating bleeding injuries; $90 \%$ indicated that they did, while only $8 \%$ indicated that they did not (question 9 , Table IV).

A large majority of respondents $(87 \%)$ indicated that more education on HIV transmission through sport was essential (question 10, Table IV).

Sources of information on the promotion of HIV awareness show that television (84\%) was the most effective medium (Table V). The least effective were managers and coaches. This again indicates the need for sport and health professionals to become more proactive on the HIVIAIDS issue.

Respondents displayed a good knowledge of the benefits of exercise for the HIV-positive individual, except with regard to maintaining weight and assistance in sleeping. A majority of the respondents ( $81 \%$ ) were aware of the psychological benefit of exercise in terms of making a person feel good (Table VI).

\section{Discussion}

A number of athletes left questions unanswered. The rea-
TABLE V. Access to information on HIV $(N=575)$

\begin{tabular}{|c|c|c|c|c|}
\hline \multirow{2}{*}{$\begin{array}{l}\text { Sources of information } \\
\text { on HIVIAIDS }\end{array}$} & \multicolumn{2}{|c|}{ Yes response } & \multicolumn{2}{|c|}{ No response } \\
\hline & $\mathbf{N}$ & $\%$ & $N$ & $\%$ \\
\hline Doctors & 296 & 51 & 279 & 49 \\
\hline Physiotherapists & 62 & 11 & 513 & 89 \\
\hline Books & 388 & 67 & 187 & 33 \\
\hline Internet & 225 & 39 & 350 & 61 \\
\hline Coaches & 116 & 20 & 459 & 80 \\
\hline Managers & 62 & 11 & 513 & 89 \\
\hline Newspapers & 431 & 75 & 144 & 25 \\
\hline Magazines & 418 & 73 & 157 & 27 \\
\hline Radio & 406 & 71 & 169 & 29 \\
\hline Television & 484 & 84 & 91 & 16 \\
\hline School & 304 & 53 & 271 & 47 \\
\hline Word of mouth & 382 & 66 & 193 & 34 \\
\hline
\end{tabular}

Table VI. Knowledge of the benefits of exercise for HIV-positive individuals

\begin{tabular}{|c|c|c|c|c|c|c|c|c|}
\hline \multirow[t]{2}{*}{ Benefits } & \multicolumn{2}{|c|}{ Yes } & \multicolumn{2}{|l|}{ No } & \multicolumn{2}{|c|}{ Usure } & \multicolumn{2}{|c|}{ No response } \\
\hline & $\bar{N}$ & $\%$ & $N$ & $\%$ & $N$ & $\%$ & $N$ & $\%$ \\
\hline Improves & & & & & & & & \\
\hline $\begin{array}{l}\text { health } \\
\text { Improves }\end{array}$ & 444 & 77 & 74 & 13 & 1 & 2 & 56 & 10 \\
\hline fitness & 453 & 78 & 68 & 12 & 1 & 2 & 53 & 9 \\
\hline $\begin{array}{l}\text { Improves } \\
\text { muscular }\end{array}$ & & & & & & & & \\
\hline strength & 448 & 78 & 69 & 12 & 1 & 2 & 57 & 10 \\
\hline Helps to control/ & & & & & & & & \\
\hline $\begin{array}{l}\text { maintain weight } \\
\text { Makes you }\end{array}$ & 385 & 67 & 101 & 18 & 1 & 2 & 88 & 15 \\
\hline feel good & 464 & 81 & 58 & 10 & 1 & 2 & 52 & 9 \\
\hline $\begin{array}{l}\text { Sleep better } \\
\text { Improves }\end{array}$ & 386 & 67 & 100 & 17 & 1 & 2 & 88 & 15 \\
\hline quality of life & 449 & 78 & 72 & 13 & 1 & 2 & 53 & 9 \\
\hline
\end{tabular}

sons for this could be that some of the questions might have been too sensitive or intrusive. A total of 900 questionnaires were handed out to athletes. Only 575 questionnaires were completed.

Table I shows that the majority of the athletes were male. These findings are similar to those of a study by the South African Sports Commission, which concluded that more males participated in sport than females (46\% versus $27 \%) .{ }^{41}$ The larger number of athletes in the over-31 age group could be attributed to older athletes who participate in athletics (long distance). Road running is currently increasing at a rate of $7 \%$ per annum. ${ }^{41}$

Although there has been speculation on the possible transmission of HIV through saliva and sweat, it has been proved that such transmission is not possible. ${ }^{9,26,51}$ Even though sweat is the most common body fluid exchanged between athletes, it is not considered a risk factor for HIV transmission among athletes. McGrew et al..$^{34}$ stated that HIV transmission risk exists if the skin is broken and infected blood enters through this route. Table II indicates that this sample of athletes were knowledgeable about HIV transmission methods generally.

Theoretically a risk exists, but most experts agree that the risk of infection during competition is extremely low, and that the principal risks faced by athletes are related to off-the-field 
activities. ${ }^{9} 10,14,23,50$ No studies have been documented on athlete-to-athlete transmission from blood exposure on the playing field, except for 1 anecdotal report of an Italian soccer player. ${ }^{48}$ However, the document rendered insufficient evidence to call the incident a conclusive case. ${ }^{10}$ Respondents in all 3 risk categories felt that HIV may be transmitted through sport participation. The data reveals that although the sportspersons were knowledgeable about the transmission modes of HIV, they still feared playing with or against infected players. This fear seems unjustified as their knowledge on modes of transmission was excellent.

There were a few concerns by sportspersons pertaining to other situations that could involve risk of transmission. These situations were blood from the eyes or mouth especially in contact sport, possible cross-infection from first aiders, openwound contact, and playing contact sport.

Most athletes (85\%) knew that contact sport posed more of a transmission risk than non-contact sport. Sports considered to involve the most potential risk are boxing, wrestling and the martial arts $^{18}$ because of close contact and risk of blood exposure from broken skin and/or membranes. Other semi-contact sports such as basketball and soccer provide opportunities for open bleeding wounds to occur, providing a theoretical possibility of HIV transmission..$^{40,49}$ The media exposure given to boxers and the compulsory HIV testing required could have convinced athletes that contact sport poses the greatest threat of HIV transmission. The South African Boxing Commission, like others worldwide, does not publish statistics on the number of HIV-infected boxers because of a serious controversy in 1995 after such disclosure..$^{30}$

Inquiry into the number of bleeding injuries sustained in the total sample during competition revealed that $37 \%$ encountered no bleeding injuries. One incident of a bleeding injury per match was reported by $30 \%$ of the sample. The highest number of bleeding injuries was reported in rugby in the high-risk category (5 or more bleeding injuries in a match). The high incidence of bleeding in contact sport necessitates that all sport personnel be educated on how to treat and control bleeding so that it does not pose a transmission risk. ${ }^{3,24}$ Only 1 case of hepatitis $B$ transmission has occurred in sport, when 5 of 10 young Japanese sumo wrestlers were infected from a teammate who bled on them during matches ${ }^{26}$ Researchers, sport and medical organisations have developed policies regarding HIV transmission in the sports world emphasising the need for universal precautions. . $^{41,23,25,40,45}$

Sports that showed most acceptances were in the individual and low-risk category. This finding is alarming due to the low incidence of bleeding injuries encountered in these sports. Low-risk individual sports like tennis afford few opportunities for physical contact. However, athletes displayed a fear of HIV transmission, which is not justified given the nature of the sport. One can only surmise that sensationalised reports of escalating infection rates have greatly contributed to fear of infection. Jackson ${ }^{25}$ sought to construct a framework for ethical deliberation concerning HIV and sport to combat the isolation experi- enced by HIV-infected individuals participating in sport.

Athletes in the Calabrese ${ }^{10}$ study questioned why it was acceptable to require testing for drugs but not for HIV. It seemed to them that society cares more about a player s drug status than his/her HIV status. HIV is the only infectious disease for which anonymous testing is publicly funded, an exception that has been controversial. ${ }^{6}$

In South Africa it is mandatory for all boxers to undergo an annual HIV-antibody test, to complete a medical examination, and to receive medical clearance before being allowed into the arena. The general exception to this is when boxers travel to the USA or to Britain where they must present results from tests conducted within the last 3 months. ${ }^{47}$ Matseka ${ }^{36}$ stated that about $9 \%$ of South African boxers have tested positive for HIV and are therefore banned from boxing. Matseka ${ }^{36}$ calculated that with the $9 \%$ incidence, boxers would have to fight 50000 bouts before transmitting the virus. The American Academy of Pediatrics Committee on Sports Medicine and Fitness, ${ }^{2}$ the World Health Organization Consensus Statement

Consultation on AIDS and Sports, ${ }^{50,51}$ the Canadian Academy of Sports Medicine Task Force on Infectious Diseases in Sports ${ }^{12}$ and the National Collegiate Athletic Association $^{37}$ have all concluded that the risk of infection from one athlete to another (even in contact sports such as football, boxing and wrestling) is not sufficient to warrant a policy of mandatory testing. Since the risk of HIV transmission in sport is not zero, many voices have advocated mandatory testing. However, several problems are associated with mandatory HIV testing. These include the high probability of false-negative and false-positive test results as well as issues regarding the right to privacy. ${ }^{39}$

Education remains the key in the effort to prevent bloodborne pathogen transmission. Sports medicine personnel play an important role in educating athletes, their families, athletic trainers, health care providers, coaches, and officials involved in sport. ${ }^{39}$ During 2002/2003 awareness was advanced mainly through the Khomanani Campaign and the lifeskills and HIV/ AIDS Education Programme in schools. ${ }^{43}$

Most research studies recommend that HIV-positive individuals exercise as most participants show improvements after commencing on an exercise programme..$^{7,27,28,30,33,35}$ The study by Rigsby et al. ${ }^{39}$ on HIV-positive individuals in stages II, III and IV, indicated that bicycle exercise training for 12 weeks significantly increased neuromuscular strength and cardiorespiratory fitness. Pedersen ${ }^{38}$ and Dudgeon et al. ${ }^{15}$ maintain that the amount of data available does not allow any strong conclusion to be drawn regarding possible beneficial or detrimental effects of training, regardless of intensity and duration, on the immune system of HIV-positive subjects. This uncertainty is caused by conflicting results found among studies. The studies by Stringer ${ }^{46,47}$ on HIV and aerobic exercise revealed that $6-12$ weeks of moderate exercise sessions ( 3 times per week for 1 hour), significantly improved aerobic capacity. Other benefits included improved functional status, improved immune function indices, maintenance of/improvements in lean body 
mass/weight, improved mood (reduced depressive symptoms) and improvement in the quality of the patient $s$ life. Recent studies by Dudgeon et al. ${ }^{15}$ concluded that the use of both aerobic and resistance exercise improves physiological parameters such as strength, endurance, time to fatigue and body composition in the HIV-infected population. Exercise has also been used successfully to treat psychological conditions such as depression and anxiety that are common in HIV-infected individuals. $^{20}$ Thus, advice to HIV-positive patients to perform physical exercise relies on the positive effects of muscle strengthening and oxygen uptake and the psychological relief achieved in those patients able to participate in a training programme.

\section{Conclusions}

In the present study $46 \%$ of respondents indicated that they would play against HIV-positive sportspersons, $18 \%$ indicated that they would not, and $34 \%$ of respondents were unsure of their views. Most athletes (85\%) knew that contact sport was more of a risk for transmission than non-contact sport.

Fifty-eight per cent of respondents believed that AIDS should be a notifiable disease in sport. A fear of contracting AIDS during sport was indicated by $59 \%$, while $37 \%$ were not afraid of transmission during sport. The largest percentage $(24 \%)$ of the respondents who indicated their fear of transmission through sport came from the high-risk category.

Eighty-seven per cent of these sportspersons wanted more information on AIDS. Coaches and doctors contributed the least towards education on the risk of HIV transmission in sport. The athletes felt strongly that coaches and doctors should go through HIV training programmes so that they can provide informed knowledge to the athletes under their supervision.

Most respondents believed that exercise should form an integral part of HIVIAIDS patients lives as it improves quality of life.

\section{Recommendations}

All athletes should complete an HIV education programme and be informed about the possibility of transmission.

Physicians, coaches and managers should counsel HIVinfected patients, especially those in boxing, as they are tested twice a year.

Coaches and managers should complete a compulsory HIV training programme before being appointed to these positions.

\section{REFERENCES}

1. Allen DM, Simelela N, Makubulo L. Epidemology of AIDS in South Africa. South African Journal of HIV Medicine 2000; July: 9-15.

2. American Academy of Pedriatrics Committee on Sports Medicine and Fitness. Human immunodeficiency virus in the athletic setting. Pedriatrics 1991; 88: 640-1.

3. Active Australia - Australian Sports Development Group. Blood Rules, OK Kit. Australia: Australian Institute of Primary Care, 2003.

4. Australian National Council on AIDS and Australian Sports 'Medicine Federation. HIV Positive People and Sport. Canberra: Australian National Council on AIDS, 1994

5. Bendix S. Industrial Relations in South Africa. Cape Town: Juta and
Company, 1992.

6. Bindman $\mathrm{AB}$, Osmond $\mathrm{D}$, Heecht FM, et al. Multistate evaluation of anonymous HIV testing and access to medical care. JAMA 1998; 280: 1416-21.

7. Birk TJ, MacArthur RD. Chronic exercise training maintains previously attained cardiopulmonary fitness in patients seropositive for human immunodeficiency virus type 1. Sports Medicine Training and Rehabilitation 1994; 5: 1-6.

8. Brown LS, Phillips RY, Brown CL, Knowlan C, Castle L Mover J. HIVIAIDS policies and sports: the national football league. Med Sci Sports Exerc 1994; 26:403-7.

9. Calabrese LH, Kelly D. AIDS and athletics. Physician and Sportsmedicine 1989; 17: 127-32.

10. Calabrese LH. HIV and sport. What is the risk? Physician and Sportsmedicine 1993; 21: 172-80.

11. Campbell C, Williams B, Gilgen D. Is social capital a useful conceptual tool for exploring community level influences on HIV infection? Aids Care 2002; 14: 41-54.

12. Canadian Academy of Sports Medicine Task Force on Infectious Disease in Sports. HIV as it relates to sport. Clin J Sport Med 1993; 3:65-6.

13. Centers for Disease Control and Prevention. Update: Trends in AIDS incidence, deaths and prevalence. Morb Mortal Wkly Rep 1997; 46: 165 73

14. Derman W. Draft Position Statement: HIVIAIDS in Sport. South Africa Sports Medicine Association and the Department of Health of South Africa, July 1997.

15. Dudgeon WD, Phillips KD, Bopp CM, Hand GA. Physiological and psychological effects of exercise interventions in HIV disease. Aids Patient Care STDs 2004; 18: 81-98.

16. Eicher ER. Contagious infections in competitive sport. Sports Science Exchange 1995; 8: 224-7.

17. Friedland GH, Klein RS. Transmission of the human mmunodeficiency virus. N Engl J Med 1987; 317:1125-35.

18. Garl T, Hrisomalos T, Rink L. Transmission of Infectious Agents during Athletic Competition: A Report to All National Governing Bodies of the US Olympic Committee Sports Medicine and Science Committee. Colorado Springs, 1991.

19. Gatheram V. HIVIAIDS in KwaZulu-Natal. The Daily News. 14 July 1999

20. Hengge UR. Testosterone replacement for hypogonadism: clinical findings and best practices. AIDS Reader 2003; 13: Suppl 12, S15-21.

21. Hamel R. AIDS: Assessing the risk among athletes. Physician and Sportsmedicine 1992; 20: 139-46.

22. Human Sciences Research Council. Human Sciences Research Council on Sport Participation in South Africa. Pretoria: HSRC, 1982.

23. Howe WB. Preventing infectious diseases in sport. Physician and Sportsmedicine 2003; 31: 78-88.

24. Hunt BP. HIVIAIDS knowledge and behaviour in a cohort of college student athletes. Journal of International Council for Health, Physical Education, Recreation, Sport and Dance 1994; 6: 121-8.

25. International Federation of Sports Medicine. AIDS and Sports. FIMS position statement. Paris: 1-4

26. Kashiwagi S, Hayashi J, Ikematsu H. An outbreak of hepatitis in members of a high school sumo wrestling club. JAMA 1982; 248: 213-4.

27. Kell R, Jenkins A. HIV transmission and sport: realities and recommendations. Strength and Conditioning 1998; 2: 58-61.

28. LaPerriere A, Flethcher MH, Antoni MH, Klimas NG, Ironson G, Schneiderman N. Aerobic exercise training in an AIDS risk group. Int $J$ Sports Med 1991; suppl 2: S53-5.

29. Lightbown R. AIDS our sporting scourge. South African Sports Illustrated 2001; Feb: 89-93.

30. Leach L. HIVIAIDS in sport. Science in Africa 2003 (http://www.scienceinafrica.com)

31. AIDS map: undermining SAs culture of violence (Editorial). Mail and Guardian; February 2003: 7-13.

32. HIVIAIDS barometer (Editorial). Mail and Guardian; August 2004: 9-10.

33. MacArthur RD, Levine SD, Birk TJ. Supervised exercise training improves cardiopulmonary fitness in HIV-infected persons. Med Sci Sports Exerc 1993; 25: 684-8.

34. McGrew C, Randall W, Schneidwind K, Gikas P. Survey of NCAA institutions concerning HIVIAIDS policies and universal precautions. Med Sci Sports Exerc 1993; 25: 917-21.

35. Mars M. HIV infection and exercise. Sports Med 2000; 2: 3-10. 
36. Matseka P. HIV and boxing. Monday Paper 1998; 17(21). Cape Town: Department of Communications, UCT.

37. National Collegiate Athletic Association. NCCA Sports Medicine Handbook 1992. AIDS and Intercollegiate Athletics. Overland Park: NCCA, 1992.

38. Pedersen BK. HIV, exercise, and immune function. In: Sankaran G, Volkwein KA, Bonsall DR, eds. HIVIAIDS in Sport. Champaign, III. Human Kinetics, 1999.

39. Rigsby LW, Dishman RR, Jackson AW, Maclean GS, Ravan RB. Effects of exercise training on men seropositive for the human immunodeficiency virus-1. Med Sci Sports Exer 1992; 24:6-12.

40. Sankaran G, Volkwein KA, Bonsall DR. HIVIAIDS in Sport: Impact, Issues, and Challenges. Champaign, III. Human Kinetics Publishers, 1999.

41. South African Sports Commission. BMI - Sport Info 2002. Pretoria: SA Sports Commission, 2002: 8-11.

42. Sanders F, Gallaway M. HIV Transmission During Sport Participation. Johannesburg: Wordsworth, 2002.
43. South African Yearbook 2003/2004. Cape Town: MacMillan: 385.

44. Schwellnus MP. AIDS in Sport: Guidelines for Prevention in Sports Participants. Cape Town: University of Cape Town / Medical Research Council, 1997.

45. Sheridan JW. Blood-borne infections in sport. Sport Medicine News 1992; 10: 2-7

46. Stringer W. HIV and aerobic exercise. Sports Med 1999; 28: 389 - 95.

47. Stringer W. Mechanisms of exercise limitations in HIV individuals. Med Sci Sports Exerc 2000; 38: S412 - 21.

48. Torre D, Sampietro C, Ferraro T. Transmission of HIV-1 via sports injury. Lancet 1990; 335: 1105.

49. Whiteside A. The state of the AIDS epidemic at the beginning of 2001. AIDS Analysis Africa 2001; 11: 3-16.

50. World Health Organization (WHO) in Collaboration with the International Federation of Sports Medicine. Consensus Statement from Consultation on AIDS and Sports. Geneva: WHO, 1989.

51. World Health Organization Consensus Statement. Consultation on AIDS and sports. JAMA 1992; 267: 1312-4. 